\title{
Research on the Development of Wenzhou Intelligent Manufacturing under Regional Economy
}

\author{
Zhuo Jing \\ Wenzhou Vocational \& Technical College, Wenzhou. 325035 \\ zhuojing@qq.com
}

Keywords: National Strategy; Intelligent Manufacturing; Enterprise; Regional Economy

\begin{abstract}
It analyzes the connotation of intelligent manufacturing from national strategic perspective, and gets the intelligent manufacturing technology field under the perspective of enterprise through analyzing intelligent manufacturing as the keyword, analyzes the key focus under current intelligent manufacture connotation and the development trend of Wenzhou Intelligent Manufacturing, which is of social significance to improve the quality of traditional manufacturing development in Wenzhou.
\end{abstract}

\section{Introduction}

The Global Intelligent Industry Conference in 2018 will be held from May 22 to 24 in Beijing Yichuang International Convention and Exhibition Center. The conference consists of five parts, including Global Intelligent Industries Conference, Intelligent Industries Conference Forum, International Innovation and Cooperation Forum, Parallel Meetings and expositions. The insiders say that the artificial intelligence development in China has entered the explosive growth period. It is predicted that till 2020, the core industry scale of artificial intelligence (AI) in China will exceed 150 billion yuan, driving the related industrial scale to exceed 1 trillion yuan. Strategic emerging industries represent the direction of a new round of scientific and technological revolution and industrial transformation, and are the key areas for cultivating new drivers and gaining new competitive advantages in the future. Information technology is centered on seeking the development in artificial intelligence, semiconductor devices, big data, infrared and Low Light Level Night Vision System, financial electronic and virtual reality/augmented reality (VR/AR). New economy drives the development of intelligent manufacturing, creating a batch of new technologies, industries and businesses, which influence the development of Chinese economy and challenges the mode of production and upper construction and supervision. In this paper, the method of literature reading is adopted to explain the development situation, basic applications and future development trend of intelligent manufacturing. In this paper, the author briefly describes the present situation and characteristics of Chinese manufacturing industry, and proposes some suggestions from the aspects of theory researches and practices of intelligent manufacturing, multidisciplinary generic technology research, information networks and security, the bottom and upper construction. 


\section{Objects of Research}

\subsection{The transformation from traditional manufacturing to intelligence}

Digital transformation refers to the comprehensive optimization of manufacturers' internal equipment and working process, establishes a shared database in the whole life cycle of enterprise products, forms useful information through data processing, uses relevant data and information to simulate the actual production process, conducts the digital management in the production process so as to optimize the production process. Digital transformation is the basis of realizing intelligent manufacturing and an indispensable step for the transformation from traditional to intelligent manufacturing.

\subsection{Industrial Clusters}

Integration generally represents applying QR code, RFID and other advanced technologies to parts and components, manufacturing equipment, raw materials and other manufacturing resources required in order to realize a high integration of vertical data resources from single equipment, production lines, workshop, factory, and even the whole industry chain. Integration is the efficient combination of software systems orienting to full lifecycle design, production, management and service and hardware equipment, including the integration of creating real-time manufacturing data, real-time analysis, dynamic instruction, etc in the process of production. Integration has become an important form of for traditional manufacturing to develop to intelligent manufacturing system. Interconnection usually refers to the interconnection between equipment and equipment, between control system and equipment and between factories and factories based on wireless and wired communication technology.

\subsection{Collaborative Innovation}

On the basis of digital transformation and integrated interconnection, the new generation of big data, the Internet of things, cloud computing and other information technologies are utilized to achieve collaborative sharing of information resources while ensuring information security. The deep integration of informatization and industrialization is the key bolster of intelligent manufacturing.

\subsection{Accelerating regional economic support on Wenzhou intelligent manufacturing}

The existing technologies are applied and innovated. Artificial intelligence, modeling and simulation technology, industrial data collection and management technology are the key to develop intelligent manufacturing. At present, the key parts of Chinese intelligent manufacturing equipment mainly rely on import without independent innovation and some important technologies, which lead to the higher production cost, influencing Chinese enterprises' intelligentization. Technological innovation is the core of intelligent manufacturing.

\subsection{Application of information technology in intelligent manufacturing regional economy}

It mainly refers to cloud computing, the Internet of things, big data and other information technology. The new generation of information technology is the basis of intelligent manufacturing and the engine to realize intelligent manufacturing. The new generation of information technology is the support of the manufacturing system and the intelligent links, and is the channel for the flow 
of manufacturing information and knowledge, which plays an important role in the intelligent manufacturing system. The analysis and mining of big data by using cloud computing technology can improve the product design, quality control, etc, so as to enable products to meet customers' needs. In addition, a new generation of information technology can effectively improve the efficiency of manufacturers' data and information processing, accelerating the interconnections of internal equipment and production lines inside and among enterprises, speeding up the vertical integration of different levels.

\subsection{Facilitating the cultivation of intelligent personnel}

The importance of employees' knowledge and management ability in intelligent manufacturing is increasingly prominent. Strengthening the training of technical leaders and personnel should be one of the key points to promote intelligent manufacturing. With the transformation and upgrading of China's traditional manufacturing, more and more high-quality professional talents will be needed. In the process of intelligent manufacturing, product design, production, management and service demand professional talents who can improve the production rate.

\subsection{Stages of Research}

The Plan of stages of research is shown in table 1.

Table 1 Plan of Stages of Research

\begin{tabular}{|c|c|c|c|c|c|c|c|c|c|c|}
\hline \multirow{2}{*}{ 寻 } & \multirow{2}{*}{\multicolumn{2}{|c|}{ Contents of the Plan }} & 2018 & \multicolumn{2}{|c|}{2018} & \multicolumn{2}{|c|}{2019} & \multicolumn{2}{|c|}{2019} & \multirow[b]{2}{*}{ Objectives } \\
\hline & & & $9-10$ & $10-11$ & 11- & $1-2$ & 2 & $3-4$ & 5 & \\
\hline 1 & $\begin{array}{l}\text { Research } \\
\text { Preparati } \\
\quad \text { on }\end{array}$ & $\begin{array}{l}\text { To implement the } \\
\text { division of labor } \\
\text { and organize } \\
\text { project }\end{array}$ & & & & & & & & $\begin{array}{l}\text { To implement the division } \\
\text { of labor }\end{array}$ \\
\hline \multirow{4}{*}{2} & \multirow{4}{*}{$\begin{array}{l}\text { Theoretic } \\
\text { al } \\
\text { research }\end{array}$} & $\begin{array}{l}\text { Background } \\
\text { research }\end{array}$ & & & & & & & & \multirow{4}{*}{$\begin{array}{l}\text { To complete the research } \\
\text { report and theoretical } \\
\text { framework; to submit the } \\
\text { research report. }\end{array}$} \\
\hline & & Document research & & & & & & & & \\
\hline & & $\begin{array}{l}\text { Correlative theory } \\
\text { research }\end{array}$ & & & & & & & & \\
\hline & & $\begin{array}{l}\text { Theory frame } \\
\text { formation }\end{array}$ & & & & & & & & \\
\hline \multirow{3}{*}{3} & \multirow{3}{*}{$\begin{array}{l}\text { Empirica } \\
\quad 1 \\
\text { research }\end{array}$} & $\begin{array}{l}\text { Practical } \\
\text { investigation }\end{array}$ & & & & & & & & \multirow{3}{*}{$\begin{array}{l}\text { To conduct analysis, } \\
\text { research and correction of } \\
\text { collected data and } \\
\text { information: }\end{array}$} \\
\hline & & $\begin{array}{l}\text { Information and } \\
\text { data collection }\end{array}$ & & & & & & & & \\
\hline & & $\begin{array}{l}\text { Analysis and } \\
\text { research }\end{array}$ & & & & & & & & \\
\hline \multirow{2}{*}{4} & \multirow{2}{*}{$\begin{array}{l}\text { Special } \\
\text { research }\end{array}$} & $\begin{array}{ll}\begin{array}{l}\text { Special } \\
\text { design }\end{array} & \text { research } \\
\end{array}$ & & & & & & & & \multirow{2}{*}{$\begin{array}{l}\text { To complete project design } \\
\text { contents and research report }\end{array}$} \\
\hline & & $\begin{array}{l}\text { Special research } \\
\text { and discussion }\end{array}$ & & & & & & & & \\
\hline \multirow{2}{*}{5} & \multirow{2}{*}{$\begin{array}{l}\text { Results } \\
\text { improve } \\
\text { ment }\end{array}$} & $\begin{array}{l}\text { Special research } \\
\text { results discussion }\end{array}$ & & & & & & & & \multirow{2}{*}{$\begin{array}{l}\text { Thesis publication and } \\
\text { concluding report }\end{array}$} \\
\hline & & $\begin{array}{l}\text { Improving research } \\
\text { contents }\end{array}$ & & & & & & & & \\
\hline 6 & $\begin{array}{l}\text { Concludi } \\
\text { ng stage }\end{array}$ & $\begin{array}{l}\text { Writing concluding } \\
\text { reports }\end{array}$ & & & & & & & & $\begin{array}{l}\text { To accomplish concluding } \\
\text { report }\end{array}$ \\
\hline
\end{tabular}




\section{Specific research methods}

\subsection{Document analysis method}

Through reading and studying a large number of related journals and literatures, a comprehensive and comprehensive understanding can be achieved on the research topic of local government promoting the strategic emerging industries. The relevant research results of scholars at home and abroad are summarized and analyzed so as to find out the problems and solutions in the development of Wenzhou's strategic emerging industries.

\subsection{Data analysis method}

The large amounts of data in the paper are selected from the national and provincial statistics, development and reform departments and all kinds of yearbook data, including many data and problems that need to be discussed in detail with the staff from related department for guiding to write the paper.

\subsection{The method of comparative analysis}

In the basis of comparing and learning from regional governments' functions and experiences at home and abroad for reference, the beneficial experience can be drawn from other regions' practices, while understanding the status quo of strategic emerging industries in Wenzhou to find out the problems and crux, so as to put forward the reasonable countermeasures and suggestions.

\subsection{The method of interviewing}

It analyzes and summarizes through discussions, interviews and questionnaire survey of government organs and industrial enterprises.

\section{The extension strategy of manufacturing value chain theory}

According to the theoretical analysis of global value chain, the industrial upgrading is mainly manifested in four aspects: upgrading in functions, technologies, chains and products. Functional upgrading generally refers to the continuous expansion of product functions, and its value extends to both ends; Technologies upgrading is the continuous improvement of product technology; Chain upgrading means expanding the development area. Product upgrading is to increase the added value of products. It is easier for manufacturers to upgrade products and processes, but more difficult to upgrade functions. To upgrade the function and extend the two ends of value chain is to grasp the knowledge of high-end value chain. To be specific, enterprises have to reserve a certain tacit knowledge; otherwise they are unable to upgrade functions. Therefore, the knowledge value chain of enterprises is one of the reasons to promote the transformation from pure manufacturing to manufacturing service industry.

\subsection{The promotion of service industries to the profits of manufacturing industry}

First of all, the key value-added link in the manufacturing industry is an important feature of service factor intensive type. Service industry belongs to the knowledge intensive one, while manufacturing industry belongs to the technology and knowledge intensive one. Service industry will take the lead in using network communication and information technology in order to strengthen the management, and the popularization of information technology in service industry 
can offer experience for the popularity of manufacturing industry, so that manufacturing can speed up the popularization, enhance production skills of workers and improve the productivity of the products.

Secondly, the value chain of manufacturing industry is closely related to services. In various production processes, a gradual separation of production space makes the connection of services more important. On the basis of the analysis of the global value chain, service connection effect is one of the important factors to ensure the normal operation of the entire value chain. In the production theories of Henryk Kierzkowski and Ronald W. Johns, it is pointed out that the effective use of service factors can promote the separation of production. Under the current conditions of international economic development, the service components in all kinds of industries are improved, reducing the production cost. The application of service components increases industry profits, so the service factors are increasingly imperative.

\subsection{The strategic path for manufacturers to achieve servitization}

Many manufacturers have only a little understanding in their product and knowledge in production, which will lead to make the manufacturing at low level, fall behind other enterprises. Manufacturing industry can use cost factor to achieve the transformation of enterprises, to improve the management mode, increase the productive rate, to get more orders and to increase the capital accumulation. For example, enterprises can strengthen their relations with international enterprises, enhance material and information exchanges and reduce logistics costs so as to promote enterprises. To save costs, they can lease a warehouse in abroad where products can be stored. Foreign suppliers can pick up the goods in basis of the market situation of the products, ensuring the timely replenishment and successful marketing of goods.

\subsection{Suggestions on promoting to implement service strategy in manufacturing industry}

(1) Problems to be avoided in the transformation and upgrading of enterprises

First of all, in the process of industrial transformation, enterprises should make use of their own advantages. Thus, first of all, they should ensure the growing of per capita capital stock. Second, China's manufacturing industry should explore a suitable path in China by combining its own national conditions, and constantly improve the domestic market development system.

In the process of transformation, enterprises should attach to the effective accumulation of funds, more than pursue the growth of quantity. The manufacturing industry should increase the proportion of service to realize the effective development, achieve sustainable investment projects, and promote their successful transformation.

(2) The complete training of personnel

When training staff, enterprises should start from the knowledge system and technical factors. With the increase of the proportion of knowledge economy, the input of knowledge factors in manufacturing industry is also increasing in the production process, as well as the demand for personnel qualities. Manufacturers can use educational training to meet the demand for talent, which will not cause the loss of talents nor form the employment difficulties of intellectuals. Besides, it can promote the development of service industry and manufacturing industry.

(3) Save the cost of environmental protection

The specific strategy for enterprises of increasing service factors and reducing environmental pollution is to increase service awareness in every production link. For example, in manufacturing a product, the manufacturer can strengthen the re-creatability of the products, and the used products can be recycled after processing so as to realize the sustainability of resource. Enterprises can extend the service life and service efficiency of equipment, saving costs. 


\section{Conclusion}

The intelligent machines in the future does not represent that a single machine has intelligent properties, but means that multiple machines, equipment, and teams can realize information mutual communication, cooperation, analysis and decision-making under the connection of a new generation of intelligent sensor, thus forming a broadly intelligent multi - body), so as to achieve intelligent integration. Future intelligent machines may be a comprehensive epitome of intelligent plants and production. In addition, to better adapt to the demand of personalized consumption, the products manufactured should meet the requirements of rapidness and agility, so intelligent machines in the future should have numerous functions ad be mobile. The existing method of decision, configuration and organization of manufacturing system has to be redesigned or improved to meet the requirements for the functions of intelligent manufacturing.

\section{Acknowledgements}

\section{The project of Wenzhou philosophy and Social Science(18wsk335)}

\section{References}

[1]Sébastien Gebus,Esko Juuso,Kauko Leiviskä. Knowledge-based linguistic equations for defect detection through functional testing of printed circuit boards[J]. Expert Systems With Applications,2007,36(1).

[2]G. Harinath Gowd,M. Venugopal Goud,K. Divya Theja,M. Gunasekhar Reddy. Optimal Selection Of Machining Parameters In CNC Turning Process Of EN-31 Using Intelligent Hybrid Decision Making Tools[J]. Procedia Engineering,2014,97.

[3]Michael D. Nunez,Joachim Vandekerckhove,Ramesh Srinivasan. How attention influences perceptual decision making: Single-trial EEG correlates of drift-diffusion model parameters[J]. Journal of Mathematical Psychology,2016.

[4]Azadeh Hassannejad Nazir,Hans Liljenström. A cortical network model of cognitive and emotional influences in human decision making[J]. BioSystems,2015,136.

[5]Michal Kremer-Asaf. How to Apply the Cybernetic Decision Making Model in Education?[J]. Procedia - Social and Behavioral Sciences,2015,209.

[6]Zeshui Xu. Group decision making model and approach based on interval preference orderings[J]. Computers \& Industrial Engineering,2013,64(3).

[7]Scott G. Heyler,Achilles A. Armenakis,Alan G. Walker,Donovan Y. Collier. A qualitative study investigating the ethical decision making process: A proposed model[J]. The Leadership Quarterly,2016,27(5).

[8]Bruce Tonn,Dorian Stiefel. Willow pond: A decentralized low-carbon future scenario[J]. Futures,2014,58.

[9]Tao Cheng,Jie Zhang,Chunhua Hu,Bo Wu,Shuzi Yang. Intelligent Machine Tools in a Distributed Network Manufacturing Mode Environment[J]. International Journal of Advanced Manufacturing Technology,2001,17(3).

[10]Jared M. Hotaling,Jerome R. Busemeyer. DFT-D: a cognitive-dynamical model of dynamic decision making[J]. Synthese,2012,189(1).

[11]Jill Anne Matusek,Margaret O'Dougherty Wright. Ethical dilemmas in treating clients with eating disorders: A review and application of an integrative ethical decision-making model[J]. European Eating Disorders Review,2010,18(6).

[12]Robin Ramcharan. Singapore's Emerging Knowledge Economy: Role of Intellectual Property and its Possible Implications for Singaporean Society[J]. The Journal of World Intellectual Property,2006,9(3).

[13]Zi-Jing Lin,Lin Li,Mary Cazzell,Hanli Liu. Atlas-guided volumetric diffuse optical tomography enhanced by generalized linear model analysis to image risk decision-making responses in young adults[J]. Human Brain Mapping,2014,35(8).

[14]Sivan Rapaport PhD,Moshe Leshno MD PhD,Lior Fink PhD. A design process for using normative models in shared decision making: a case study in the context of prenatal testing[J]. Health Expectations,2014,17(6).

[15]Rebecca A. Scott,Benjamin T. George,Victor R. Prybutok. A Public Transportation Decision-Making Model within a Metropolitan Area[J]. Decision Sciences,2016,47(6).

[16]Darren Southwell,Reid Tingley,Michael Bode,Emily Nicholson,Ben L. Phillips. Cost and feasibility of a barrier to halt the spread of invasive cane toads in arid A ustralia: incorporating expert knowledge into model-based decision-making[J]. Journal of Applied Ecology,2017,54(1).

[17]Asano Masanari,Ohya Masanori,Tanaka Yoshiharu,Basieva Irina,Khrennikov Andrei. Quantum-like model of 
brain's functioning: decision making from decoherence.[J]. Journal of Theoretical Biology,2011,281(1).

[18]Michael D. Nunez,Joachim Vandekerckhove,Ramesh Srinivasan. How attention influences perceptual decision making: Single-trial EEG correlates of drift-diffusion model parameters[J]. Journal of Mathematical Psychology,2017,76.

[19]Jiayu Jin,Liyan Han. Assessment of Chinese green funds: Performance and industry allocation[J]. Journal of Cleaner Production,2018,171.

[20]Dániel Tokody. Digitising the European industry - holonic systems approach[J]. Procedia Manufacturing,2018,22.

[21]Oliver Fisher,Nicholas Watson,Laura Porcu,Darren Bacon,Martin Rigley,Rachel L. Gomes. Cloud manufacturing as a sustainable process manufacturing route[J]. Journal of Manufacturing Systems,2018,47.

[22]Wen-Shiung Lee. Merger and acquisition evaluation and decision making model[J]. The Service Industries Journal,2013,33(15-16). 